\title{
University Professional and Managerial Staff: Information Needs and Seeking
}

\section{Janie L. Hassard Wilkins and Gloria J. Leckie}

This study examines the work-related information needed and sought by professional and managerial staff of a large university. Through personal contacts, the Internet, and departmental sources, professional staff are able to readily satisfy many of their daily and short-term work-related information needs with minimal use of the library. However, because their jobs are multifaceted and complex, these staff members frequently are engaged in longer-term activities (such as project development, report writing) requiring more intensive library use, which often is perceived to be frustrating and time-consuming. The implications of these findings for academic libraries are discussed.

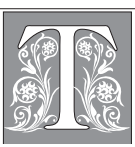

he ways in which people access and use information to meet their work-related information needs has become an important area of research in library and information science (LIS). Numerous studies have examined the ways in which individuals employed in specific occupations and professions (such as health care, teaching, scientific research, management, or engineering) gather and use information in the course of their daily work as professionals.1 Although LIS research has expanded over the years to examine a diversity of professions and occupational settings, various occupational groups continue to be overlooked. This is certainly true of the professional and administrative staff working in insitutions of higher education.

The professional and administrative staff of a university are a large and influential group, responsible for the day-to-day operation, management, and planning of the university or college, yet suprisingly little is known about their needs for information or their information-seeking patterns. This is undoubtedly because the literature on information seeking in academic institutions has concentrated very heavily upon understanding the information needs of scholars and students, thus somewhat marginalizing the needs of other individuals who also are key participants in the daily functioning of these institutions. ${ }^{2}$ This study, then,

Janie Wilkins is Reference/Interlibrary Loan Librarian in the Warren Hunting Smith Library at Hobart and William Smith Colleges; e-mail: wilkins@hws.edu. Gloria J. Leckie is an Associate Professor in the Graduate Program in Library and Information Science at the University of Western Ontario; e-mail: leckie@julian.uwo.ca. 
is one of the few attempts to examine the information seeking of professional and managerial staff employed by an institution of higher learning.

\section{Previous Research}

A review of the literature indicates that there have been only a few studies to date that have considered the information seeking of university professional and managerial staff. Peter G. Watson briefly detailed the findings from a small pilot study conducted at the Meriam Library of California State UniversityChico.3 The intent of the trial was to determine whether the library system could assist six senior administrators in the performance of their duties by offering them the services of a librarian to help with information retrieval. The administrators generally felt that the service offered them was very useful and that all administrators could benefit from similar services. In a more in-depth follow-up article, Watson and Rebecca A. Boone put forth both a rationale and a model for providing direct information support for academic administrators. 4 Based on the pilot study, they identified a number of questions that arose in providing specialized library service to academic administrators, including: Is it the role of the library to provide this level of service? Can the level of service be sustained within the context of normal library operations? What about issues of confidentiality? Is the library prepared to search out sources that it does not have in order to answer administrators' requests? Despite the problems, the authors concluded that providing an information support service for administrators would be of benefit to both administrators and the library system.

In a similar vein, Sherman Hayes argued that the academic library must find ways to better serve the professional staff in institutions of higher education, as the information needs of this user group have greatly expanded in recent years. ${ }^{5}$ Hayes noted that professional, nonfaculty staff members on campuses in the 1990s are responsible for an increasingly wide range of activities requiring information on topics as diverse as health and safety regulations, energy efficiency, handicapped access, counseling, fund-raising, financial services, building maintenance, and personnel management, and that their information needs generally are not well served by the library or other campus information systems.

Although the previous articles suggest some compelling reasons for the academic library to become involved in meeting the information needs of the professional staff on campus, the question of how university administrative and professional staff actually go about seeking information in the course of their daily work is not addressed in detail. What is the nature of their work, and how does it shape their requirements for information? Does the academic library even play a role in their information-seeking patterns? To explore these questions, Mary W. Sprague conducted a survey of a sample of administrative and professional staff at Ohio State University. Her survey resulted in responses from 236 staff members (72\% response rate). Consistent with the findings about other occupational groups, Sprague found that interpersonal contacts were the most frequent sources of information for university administrative and professional staff. However, job-specific print materials also were extremely important. Accuracy was by far the most important criterion in information seeking, with almost 50 percent of respondents citing this factor. In assessing library use by professional staff, Sprague found that only 36 percent of respondents used the library in relation to their work. 
Patterns of library use differed with demographic characteristics: Individuals with a higher level of education tended to use the library more frequently, and younger respondents (as well as those with less than ten years of service to the university) also used the library more regularly than others. Sprague concluded by noting that because professional staff do not appear to use library access tools, more user-friendly access tools at the desktop are warranted, and more tailored bibliographic instruction for this group would be useful. She also pointed out that although many professional staff reported that they did not need libraries in their information seeking, it was apparent that they often were unaware of what was available to them through the library system.

\section{Objectives and Methodology}

Because there are so few studies of university administrative and professional staff in the literature, it was decided to expand on earlier research by examining the information seeking of nonfaculty professional and managerial staff members employed at a Canadian university. The study had three objectives: (1) to examine, in general, the information-seeking habits of the nonfaculty professional and managerial staff of a large academic institution, namely the University of Western Ontario; (2) to explore what role (if any) the campus library system played in meeting the information needs of this group; and (3) to test the critical incident technique as a methodology for gaining a more detailed understanding of the interrelationships between the nature of professional and administrative work within the university setting and the information needs that arise from such work.

To meet the first two objectives, a questionnaire was designed. The first part of the questionnaire was crafted to elicit information on the nature of the work done by professional and managerial staff, the types and sources of information required in their work, and the ways in which staff members routinely sought information when they had an information need related to their job. The second part of the survey explored how often the campus library system was used, types of materials used, principal reasons for visiting the library, and awareness/use of the resources available through the library's electronic network.

The survey was conducted during the spring and summer of 1996 at the University of Western Ontario (UWO) in London, Ontario. To attain a representative sample of the professional and managerial staff on campus, it was decided to survey the membership of the Professional and Managerial Association (PMA) at the university. The executive of the PMA agreed to support the study, and that support was instrumental in compiling the mailing list and encouraging members to respond to the survey.

A pretest was conducted in May 1996, and as a result, minor modifications were made to the survey instrument based on the feedback. The final survey was distributed in early June via the campus mail system. The mailout of 363 surveys was based on the membership roster of the PMA at UWO as of May 31, 1996.

To meet the third objective, follow-up individual interviews were planned, to be conducted using the critical incident technique. It was hoped that use of the critical incident technique would provide case studies that would support and add depth to the quantitative results of the survey. To solicit interview subjects, an interview participant form was included with the survey package, asking staff members to return the form if they would be willing to be interviewed about their work and their information seeking. Interview 


\begin{tabular}{|c|c|c|}
\hline \multicolumn{3}{|c|}{$\begin{array}{c}\text { TABLE } 1 \\
\text { Primary Areas of Work Activity }\end{array}$} \\
\hline & $\mathrm{N}$ & $\%$ \\
\hline Managerial/supervisory & 65 & 44 \\
\hline Providing services to students & 36 & 24 \\
\hline Administration & 36 & 24 \\
\hline Technical/computer support & 34 & 23 \\
\hline Providing services to employees & 18 & 12 \\
\hline Financial services & 15 & 10 \\
\hline Marketing/development & 7 & 5 \\
\hline Research & 6 & 4 \\
\hline Other & 8 & 5 \\
\hline
\end{tabular}

participants were asked to recall a "criti-

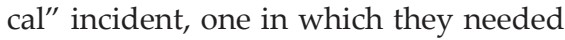
information in order to complete an important task related to their job. They then were to describe the steps they took to have their information needs fulfilled. Participants also were asked to detail the sources they consulted and to identify problems or roadblocks they encountered while trying to satisfy their information needs. Finally, they were asked about the outcomes of their information searching (e.g., Did they find the information they required and, if so, where?).

\section{Survey Respondents}

One hundred and forty-eight surveys were returned from the initial sample of 363 , for a response rate of 41 percent. All of the returned surveys were usable. The Statistical Package for the Social Sciences (SPSS for Windows) was used for data analysis. The original twelve questions contained in the survey were recoded for data entry, resulting in the formation of fifty-six separate variables that could be examined and analyzed.

In terms of demographic information, respondents were asked to indicate both their level of education and the number of years they had been employed by the university. The profile of professional and managerial staff that emerged from the survey was that of a highly educated group, the large majority of whom had worked for the university for more than ten years. The majority (102, or $69 \%$ ) of the respondents had completed a university degree, with 31 percent having a B.A.; 32 percent, a master's degree; and 5 percent, a Ph.D. Of the remaining respondents, 26 percent had completed a diploma and 5 percent had other qualifications or certification. Many of the respondents $(78$, or $53 \%)$ had worked for the university between ten and twenty years, and a further twenty-nine (20\%) had twenty-one years or more of service. The effects of fiscal constraints upon university hiring are certainly evident in the data. Although a large proportion of the respondents fell into the thirteen- to sixteen-year range of service, only six (4\%) had been hired by the university in the past three years.

With respect to the work done by respondents, developing an accurate picture proved to be more difficult. The PMA is a diverse group, including professionals and managers from a variety of departments on campus. Some of these departments represent specific disciplines or schools within the university, whereas others are related to the administrative functioning of the university (such as finance or institutional planning) or the physical plant. It became obvious through the pretest that many of the individuals who belong to PMA hold positions that are multifunctional in nature, meaning that it is difficult for them to identify one primary area of activity. For this reason, designing a question that would allow the respondents to accurately reflect the nature of their jobs was challenging. Respondents were asked to identify their primary area of activity from a list of seven choices, but they also were given the option of selecting two areas, if needed. 
Some respondents, however, identified three areas that described their primary areas of activity.

Despite these difficulties, some generalizations can be made (see table 1). The highest number of respondents (65, or $44 \%$ ) were involved in managerial and supervisory activities. However, three other areas also were ticked frequently by staff members, including administration $(24 \%)$, provision of direct services to students (24\%), and technical and computer support (23\%). Providing service to UWO personnel, financial services, and marketing were noted less frequently. Finally, fourteen respondents indicated that they had other primary areas of responsibility outside the seven choices provided, the single largest of which was research, including both research done in support of university operations and disciplinebased research $(6$, or $4 \%)$. Other responses included architectural design, purchasing, clinical veterinary medicine, mechanical support, and service to the community.

\section{Information Sources and Formats}

Respondents were asked to report on the types of information they needed in

\section{TABLE 2}

Types of Information Required for Job Performance

Professional literature Respondents \%*

$122 \quad 82$

Internal UWO information

$105 \quad 71$

$99 \quad 67$

$76 \quad 51$

$68 \quad 46$

$68 \quad 46$

$48 \quad 32$

$48 \quad 32$

$46 \quad 31$

$32 \quad 22$

10

7

*Note: Percentages do not total 100 because respondents could indicate more than one type of information. order to perform their jobs (see table 2). Respondents indicated that the category "professional literature/current developments in their fields" was the type of information needed by an overwhelming majority (82\%), followed closely by internal university information and regulations (71\%). More than half of the respondents indicated that they needed technical literature/manuals (67\%) and supplier information (51\%), whereas just under half needed general management literature (46\%) and government regulations (46\%). The types of information used by the fewest number of respondents included external statistics, market re-

\begin{tabular}{|c|c|c|c|}
\hline \multicolumn{4}{|c|}{$\begin{array}{c}\text { TABLE } 3 \\
\begin{array}{c}\text { Importance of Personal \& Institutional Sources of Information } \\
\text { for Job Performance }\end{array}\end{array}$} \\
\hline & $\begin{array}{c}\text { Not/Somewhat } \\
(1-2)\end{array}$ & $\begin{array}{c}\text { Important } \\
\text { (3) }\end{array}$ & $\begin{array}{c}\text { Very/Extremely } \\
(4-5)\end{array}$ \\
\hline Co-workers & $7(5 \%)$ & $32(22 \%)$ & $109(74 \%)$ \\
\hline Other professional contacts & $12(8 \%)$ & $29(20 \%)$ & $106(72 \%)$ \\
\hline Departmental sources & $6(4 \%)$ & $35(24 \%)$ & $107(72 \%)$ \\
\hline UWO library system & $82(56 \%)$ & $36(25 \%)$ & $28(19 \%)$ \\
\hline Public library system & $132(92 \%)$ & $11(7 \%)$ & $3(2 \%)$ \\
\hline Professional associations & $52(36 \%)$ & $40(28 \%)$ & $51(36 \%)$ \\
\hline Conferences/workshops/courses & $31(21 \%)$ & $48(33 \%)$ & $68(46 \%)$ \\
\hline
\end{tabular}




\begin{tabular}{|l|c|c|c|}
\hline \multicolumn{4}{|c|}{ TABLE 4 } \\
\hline & $\begin{array}{c}\text { Not/Somewhat } \\
(\mathbf{1 - 2})\end{array}$ & $\begin{array}{c}\text { Important } \\
\mathbf{( 3 )}\end{array}$ & $\begin{array}{c}\text { Very/Extremely } \\
\mathbf{( 4 - 5 )}\end{array}$ \\
\hline \hline Journals & $37(25 \%)$ & $49(28 \%)$ & $69(47 \%)$ \\
Newspapers & $85(58 \%)$ & $33(23 \%)$ & $28(19 \%)$ \\
Conference papers & $61(44 \%)$ & $39(27 \%)$ & $43(29 \%)$ \\
Reference books & $22(15 \%)$ & $27(18 \%)$ & $98(67 \%)$ \\
Books & $39(27 \%)$ & $44(30 \%)$ & $63(43 \%)$ \\
Other paper formats & $39(54 \%)$ & $9(13 \%)$ & $24(33 \%)$ \\
UWO databases & $47(32 \%)$ & $30(21 \%)$ & $69(47 \%)$ \\
Information retrieval & & & \\
databases Or CD- & $91(64 \%)$ & $18(13 \%)$ & $33(23 \%)$ \\
ROMs & $45(31 \%)$ & $33(22 \%)$ & $69(47 \%)$ \\
Internet & $43(66 \%)$ & $4(6 \%)$ & $18(28 \%)$ \\
Other electronic & & & \\
formats & &
\end{tabular}

search, business and trade publications, and financial management literature.

Respondents then were asked to rank the importance of various personal or institutional sources of information on a scale of one to five, with "five" representing an extremely important source and "one" representing those not important. As table 3 demonstrates, most respondents clearly felt that coworkers were their most important source of information, with 74 percent ranking them as being either extremely important (52\%) or very important $(22 \%)$. A similar pattern also can be found when respondents ranked the importance of other professional contacts, with 72 percent indicating that professional contacts were either extremely or very important sources of information. These findings are consistent with the literature on information seeking, a significant finding of which "is the generally felt preference of information-seeking individuals for interpersonal sources, across demographic variations or categories of information need." Also consistent with the literature is the finding that 72 percent of the respondents noted that departmental sources were extremely or very important in the performance of their jobs. This corresponds to numerous studies which have shown that workers across a variety of occupations often prefer to use sources that are close at hand (referred to informally as the "arm'slength rule"), even though there may be better sources available elsewhere. ${ }^{1}$

Libraries do not figure very prominently as information sources for university professional staff. The UWO library system is more important to people as a source of information than the public library, but it is much less important than the sources discussed above. Although 19 percent ranked the UWO library system as being either important or extremely important, a much larger proportion (56\%) indicated that the library system was generally not very important. By comparison, 91 percent of respondents indicated that the public library was slightly or not important. It should be noted, however, that 25 percent did rank the UWO library system as being important as a source 
of information, whereas only 7 percent ranked the public library in this category.

After ranking the importance of sources of information, respondents were asked to use the same five-point scale to rank the importance of various information formats (e.g., journals, newspapers, the Internet). A number of interesting findings emerged from this ranking.

First, as was anticipated, print sources featured very prominently as important information formats (see table

4). Reference books were the most important format. Eighty-five percent of respondents ranked reference books as important to extremely important $(67 \%$ ranked them in the two highest categories of importance). This finding was somewhat unexpected given the responses to an earlier question that showed current awareness literature (which is usually in journal format) to be the most frequently needed type of information. Indeed, journals were ranked as important by 75 percent of respondents, followed closely by books (73\%).

A second unanticipated finding was the relative importance of the Internet, ranked as being important to extremely important by 69 percent of respondents. This finding demonstrates how rapidly the Internet has permeated university structures, because in Sprague's 1994 study, the Internet did not feature prominently as an important source of information for staff. ${ }^{1}$ Internal UWO databases also were ranked highly, with over 68 percent of respondents ranking this format as being important to extremely important. This finding compares very well with other studies of administrative work showing that internal databases and
TABLE 5

Reasons for Campus Library Use

\begin{tabular}{c|r} 
Yes & \multicolumn{1}{|c}{ No } \\
\hline $35(24 \%)$ & $112(76 \%)$ \\
$88(60 \%)$ & $59(40 \%)$ \\
$23(15 \%)$ & $123(85 \%)$ \\
$43(29 \%)$ & $104(71 \%)$ \\
$25(15 \%)$ & $125(85 \%)$ \\
$19(13 \%)$ & $128(87 \%)$ \\
$26(25 \%)$ & $111(75 \%)$ \\
$9(6 \%)$ & $138(94 \%)$ \\
\hline
\end{tabular}

records are primary sources of information for most employees. ${ }^{1}$ In comparison, other information retrieval systems and CD-ROM databases were considered to be the least important formats needed for locating information, with 64 percent of respondents indicating that they were not very important.

Respondents also identified other formats of information, both electronic and paper based, that were important to them in the performance of their jobs. For instance, five respondents indicated that newsletters were an important format. Other formats listed included brochures, pamphlets, posters, technical drawings, faxes, and financial reports.

\section{Library Use}

When campus library use was examined, the most frequent response $(37 \%)$ was for PMA members to use the campus library system two to six times per year. However, it should be noted that almost 30 percent indicated that they never used the campus library system, and only 7 percent were heavy library users (i.e., on a weekly basis).

The reasons for using the library are detailed in table 5. The most common reason $(60 \%$ of respondents for that ques- 


\begin{tabular}{|c|c|c|}
\hline \multicolumn{3}{|c|}{$\begin{array}{c}\text { TABLE } 6 \\
\text { Information Resources Used in Campus } \\
\text { Libraries }\end{array}$} \\
\hline & Yes & No \\
\hline Journal literature & $70(48 \%)$ & $76(52 \%)$ \\
\hline Popular magazines & $33(22 \%)$ & $114(78 \%)$ \\
\hline Newspapers & $23(16 \%)$ & $124(84 \%)$ \\
\hline $\begin{array}{l}\text { CD-ROMs/electronic } \\
\text { sources }\end{array}$ & $29(20 \%)$ & $118(80 \%)$ \\
\hline Reference books & $78(53 \%)$ & $68(47 \%)$ \\
\hline Government documents & $27(18 \%)$ & $120(82 \%)$ \\
\hline Scholarly books & $43(29 \%)$ & $103(70 \%)$ \\
\hline Light reading materials & $21(14 \%)$ & $126(86 \%)$ \\
\hline Other & $2(1 \%)$ & $145(99 \%)$ \\
\hline
\end{tabular}

visited the library to use materials such as government documents, newspapers, CD-ROMs, and electronic sources. Finally, although about a quarter of respondents indicated in an earlier question that they used campus libraries for pleasure or self-improvement, in response to this question, only 14 percent indicated that leisure or light-reading materials were sought at the library.

In response to the question, "How often do you access the UWO Library Network (LibNet) from your office or home?" the majority of respondents (57\%) indicated that they never used LibNet, tion) was to use the library for research related to the job. However, using the library for personal reasons also was very much in evidence. Twenty-nine percent of respondents used campus libraries to conduct personal research, and 24 percent used it for reasons of pleasure or self-improvement. As well, 25 percent used campus libraries because of convenient locations (compared to the public library). The least common reasons for using the library included those related to library services: only 15 percent of the respondents visited the library to consult with a reference librarian and even fewer respondents $(13 \%)$ used the library for database searching.

Respondents were asked to indicate what types of library materials they tended to use (see table 6). It was found that when respondents visited a library on campus, the majority (53\%) did so to consult a reference book, such as a handbook or directory, which fits in very well with the previous finding that the majority of staff indicated that they need reference materials in order to do their work. Other materials used frequently included scholarly journals (48\%) and scholarly books (29\%). Less than $20 \%$ of respondents with much smaller proportions using it occasionally $(29 \%)$ or frequently $(14 \%)$. Respondents who had indicated that they had never used LibNet were then asked to describe why they did not use the service. The primary reason cited was a lack of awareness about the existence of the network ( $57 \%$ of respondents). Of the remaining 42 percent who were aware of LibNet but did not use it, the most common explanation was that respondents had no reason to make use of it ( $62 \%$ of those responding to this question). However, 14 percent of respondents stated that they did not use it because they did not know how to gain access, and another 8 percent stated that they did not have access to a computer at work or home.

When respondents were asked, "Would you characterize yourself, overall, as being a user or nonuser of the UWO library system?" the responses were equally divided, with 50 percent of the respondents characterizing themselves as users and 50 percent as nonusers. Those classifying themselves as users also were asked to give their main reason for using the library system. Most identified reasons relating to work $(65 \%)$, or equally for 
work and personal reasons (27\%). However, 8 percent indicated that they used the library system primarily for personal reasons.

Finally, the variables concerning library use were cross-tabulated against work-area and demographic variables. Cross-tabulation revealed that a higher proportion of employees involved in providing direct services to students considered themselves to be library users than employees working in other areas. This result may have occurred because some librarians were PMA members and thus were included in the sample, causing the response to this question to be disproportionately higher. However, it also could be that employees providing direct services to students (such as career counselors, educational specialists, therapists, doctors, nurses) do, in fact, use the library more often. This is in contrast to employees involved in technical/computer support, who were more likely to consider themselves nonusers. In the other work areas, there was a balance between those who considered themselves library users and those who did not, so that no clear pattern was evident.

Demographic variables included years employed at the university and education. Cross-tabulation of years employed with library use and LibNet use did not reveal any noticeable trends. To explore this further, correlation was carried out, revealing no significant relationships. In other words, length of service at the university was unrelated to use of either the library or its electronic network (although Sprague did find a significant association between years of employment and library use). ${ }^{1}$

Education, however, proved to be a different matter. Cross-tabulations revealed that a higher proportion of those with master's degrees and Ph.D.'s considered themselves to be library users, used the library more frequently, and used LibNet. Correlations also were performed, in all cases showing significant relationships ( $p$ $<.01$ ) between these variables, as Sprague also found. ${ }^{1}$ It seems, therefore, that professional and managerial employees with graduate degrees are more likely to be library users, to use the library more frequently, and to use LibNet than are employees who have either bachelor's degrees or diplomas.

\section{Critical Incident Interviews}

Interview participants were selected from a total of twenty-one volunteers who had indicated they would be willing to be interviewed. Due to timing constraints, only five critical incident interviews were carried out, during July 1996. An attempt was made to have the interview participants represent a cross section of the population, so that interviews were not conducted with participants who did similar kinds of work. The five subjects selected for the critical incident interviews thus represented the diverse work activities of the PMA membership as a whole.

The interviews confirmed some of the survey findings and, as was hoped, provided further insights into the information-seeking patterns of professional and administrative staff. Four of the critical incidents described involved writing major reports or proposals on a variety of topics (student services, equipment maintenance, professional development, census analysis), and the fifth incident involved intervention in a crisis situation requiring an immediate change in university procedures.

The interviews revealed that although their position titles were dissimilar, the participants shared many commonalities with respect to the nature of their work and the information needed, sought, and used in relation to it. One noticeable commonality was that most of the participants' 
positions required a significant amount of research and writing. This research/writing role created very complex information problems, not easily resolved through a single source or a single search. Watson and Boone made a similar observation about the work of university administrators, commenting that they had to deal with long-term, complex issues resulting in new campus regulations or policies. ${ }^{1}$ In this respect, professional/managerial staff are not unlike faculty members conducting literature-based research. Although the nature of the research and writing done by the two groups is quite different, the research processes and information needs prompted by these activities may, in fact, be quite similar. For instance, the participants complained of having difficulty narrowing the focus of their research reports and of having too many potential sources of information to search. They often found crucial pieces of information through browsing or serendipity, or through referral from colleagues. Several of them had research assistants to whom they delegated literature searching. Most of the participants felt that their own information retrieval skills were lacking, that they did not feel confident in using databases or the library catalog, and that they wasted time in conducting their searches because of their lack of proficiency. Libraries were viewed as useful particularly for tracking down and verifying citations already known to the researcher, but reference librarians were rarely consulted. Interestingly, many of the same observations have been made in numerous studies of university faculty. ${ }^{1}$

A second very striking commonality among the staff members interviewed was use of the Internet and reliance on a "virtual invisible college." ${ }^{1}$ In the case of the crisis incident described by one participant, a posting was sent to a listserv he frequently used, resulting in ten responses the same day from experts in the field and thus enabling him to solve his problem quickly and efficiently. Other participants noted the importance of keeping in touch through the Internet with a far-flung network of colleagues who did similar work. The Internet also was mentioned by four of the five participants as a first choice in information seeking, often giving them key leads (such as bibliographies) that then could be followed up through more conventional sources.

A third theme was the importance of internal information resources. Most of the participants maintained some sort of personal library consisting of frequently used reference books and manuals, and a few key journals. In some cases, their personal libraries were crucial to their work because the university library system did not have relevant materials in its collection. In addition, all the participants mentioned the importance of access to various UWO databases, such as student or financial records.

A final area of commonality was a concern over keeping current. Participants complained that it was increasingly difficult to keep up with developments in their fields or with information they needed to be well informed in their positions, a problem that also was noted in other studies of professional employees. ${ }^{1}$ Journals seemed to be the preferred method of keeping current, although one participant also read a number of daily newspapers on the Internet to help her keep abreast of relevant events.

\section{Discussion}

When the findings of the survey and critical incident interviews are taken together, some interesting observations about university professional and managerial staff can be made. The professional and managerial staff participating in this research were a highly educated group 
with long service to the university (most with ten years or more). The work carried out by this group was multifaceted and complex, consisting of ongoing daily administrative and managerial activities as well as major projects of longer duration. As a result, information needs seemed to be of two types: those prompted by daily managerial/professional routines or crises (short term) and those that arose from longer-term planning situations or special projects.

As Watson and Boone point out, these different kinds of information needs undoubtedly require different responses. “Every office engaged in academic administration keeps a set of indispensable tools of the trade on the shelf; these are, in effect, the ready-reference sources for higher education administration and will provide answers to a large percentage of the daily need for names, numbers, facts and figures."1 This suggestion was borne out in this survey, where a large proportion of respondents indicated that reference books, technical manuals, and university and government regulations were the type of information they required to do their jobs on a daily basis. These information sources were most likely to be found within the staff member's own department or area, through either asking colleagues and/or consulting print resources or internal databases. In addition, it was evident from both survey and interview responses that the Internet had become an increasingly important source for retrieving quick information.

On the other hand, professional and managerial staff frequently also were engaged in projects of longer duration, requiring numerous sources of information not readily at hand. The end result of these projects usually was a written report or proposal, often on a new issue that had to be considered in developing university programs and policies. When engaged in such projects, the information needs of professional staff are not unlike those of faculty members engaged in the early stages of a research project. If these interview participants are typical, staff members frequently had difficulty narrowing the scope of their research topic and thus also had difficulty identifying and gathering relevant information. Although database (including the library catalog) searches often were required to generate useful citations, professional staff perceived their own information retrieval skills to be weak and thus felt that they wasted valuable time in attempting to conduct searches themselves. Despite this, survey responses revealed that surprisingly few ever consulted reference librarians for assistance, although some staff did delegate searches to research assistants. These observations correspond closely to Sprague's findings that few professional staff "use access tools such as the online catalog, a librarian, printed indexes, or electronic databases." 2

Use of the university library system by the professional and mangerial staff in this study was uneven. Although about a third of the survey respondents indicated that they used campus libraries frequently, the majority used them only rarely or never. The primary reason for this pattern of usage was the perception that there was no need to use the library in relation to their work, suggesting perhaps that, for the most part, departmental resources and colleagues are adequate information sources. Despite this possibility, however, a large number of participants indicated that the Internet was a frequently used source of information. Is this purely a matter of desktop convenience, a variation of the informal arm's-length rule? Convenience does not appear to tell the whole story, however, because other electronic sources also available at the desktop through the library's electronic 
network were not being utilized, largely because staff either did not know about the library network or did not know how to gain access to it.

It does seem, as Sprague strongly suggests, that professional and managerial staff could benefit from some library-oriented instructional workshops tailored to their needs. ${ }^{2}$ The problem, however, is one of timing. The extensive literature on bibliographic instruction stresses that user education is more likely to be successful if delivered at the time of need, especially when the individuals concerned have a project requiring heavier use of library resources. Staff members, such as faculty, appear to be able to solve many of their daily information needs on their own and are not engaged in complex projects all the time. The question that then arises is how to make them aware of the library system's resources (including both materials and personnel) at the time they are engaged in intensive research and writing and do need to make use of a wider range of information sources. At the very least, more creative approaches to marketing library resources and services to this group appear to be warranted.

Related to the previous point, a second issue to consider is the nature of the typical academic library's collection. Survey respondents indicated that the information resources needed on a daily basis were often specialized reference tools (handbooks, technical manuals, suppliers' catalogs, internal university regulations, etc.) or specific professional journals, yet these resources usually are not the type of material collected by academic libraries because they become quickly outdated or are irrelevant to students and faculty engaged in disciplinary research. Thus, it seems unlikely that in an era of stagnant collections budgets, academic libraries will see fit to place a priority on meeting the short-term information needs of professional staff. However, the long-term information needs of professional staff appear to be a different matter. Interview participants who did make use of the library with respect to a project or proposal described needing the types of information resources that academic libraries already have, such as the library catalog, the ERIC database, census data on CD-ROM, and other statistical sources. Ironically, survey responses indicated that professional staff rarely made use of such resources even though they were readily available. Is this because of unfamiliarity with what the library system has, the types of information that could be retrieved, and/or the role of librarians in facilitating retrieval? Again, this brings us back to the conclusion that more effective marketing and the development of tailored workshops could greatly assist professional and managerial employees in making more effective use of existing library resources and services.

\section{Conclusions}

University staff who are described as professional and managerial represent a wide range of professions and managerial responsibilities. Like faculty, many of them have preferred means (such as asking colleagues) of finding information relevant to their work and desire to be independent information seekers. As such, it probably is futile to think that the campus library system can, or ought, to play an aggressive role in meeting the ongoing information needs of this group as a whole. However, evidence from this study and others suggests that, at critical times, certain professional and managerial staff do have long-term information needs that could be met through either use of the resources of campus libraries or interactions with library personnel skilled in information retrieval.

But what are those critical times, and 
which professional staff are likely to be engaged in such activities? The answer may lie not in consideration of the positions that professional and managerial staff hold but, rather, in the roles they play within their positions, as other studies have suggested. ${ }^{2}$ This exploratory research has pinpointed one role (researcher/writer) that many professional staff find themselves taking on which requires more intensive and concentrated information seeking than is typical on a daily basis. Undoubtedly, there are other roles (such as planner, mediator, fundraiser, administrator) or tasks (such as budgeting, personnel management) that are equally demanding of a higher level of information gathering. Thus, it is suggested that our understanding of the information needs and information-seeking patterns of professional and managerial employees could be greatly enhanced through future research examining (1) the common roles in which such staff are engaged, (2) the specific work-related projects or tasks arising from those roles, and (3) identification of information-seeking activities arising from particular projects that could be enhanced through the use of university library systems. As Watson and Boone argue, any efforts in this direction should be with the goal of enabling university employees at all levels to make more informed and effective decisions in running the university. ${ }^{2}$

Finally, the critical incident interviews used in this study provided an extremely rich source of additional data on the nature of both the participants' work worlds and their information seeking. Although very labor-intensive (in terms of conducting, taping, and transcribing the interviews), the data thus gained were in many ways more revealing than those gained through the survey methodology, suggesting avenues for exploration that could not have been easily evoked through a survey instrument alone. Thus, it is further suggested that, with a much larger sample, the critical incident approach would seem to be a highly useful and appropriate methodology for more meaningful and detailed research on this topic.

The authors would like to thank Michelle Colpitts and the executive of the Professional and Managerial Association of the University of Western Ontario for their interest in, and assistance with, this project.

\section{Notes}

1. This research tends to be scattered, but two useful overviews are Elizabeth Hewins, "Information Needs and Use Studies," Annual Review of Information Science and Technology 25 (1990): 145-72; and Gloria Leckie, Karen Pettigrew, and Christian Sylvain, "Modelling the Information Seeking of Professionals," Library Quarterly 66 (Apr. 1996): 161-93.

2. Examples include Stephen Wiberly and William Jones, "Patterns of Information Seeking in the Humanities," C\&RL 50 (Nov. 1989): 638-45; Donald Case, "The Collection and Use of Information by Some American Historians: A Study of Motives and Methods," Library Quarterly 61 (Jan. 1991): 61-82; Barbara Fister, "The Research Processes of Undergraduate Students," Journal of Academic Librarianship 18 (July 1992): 163-69.

3. Peter G. Watson, "Information for Administrators," College E Research Libraries News 49 (Jan. 1988): 5-6.

4. Peter G. Watson and Rebecca A. Boone, "Information Support for Academic Administrators: A New Role for the Library," CERL 50 (Jan.1989): 65-75.

5. Sherman Hayes, "Serving the Professional Staff in Higher Education," College E Research Library News 51 (Dec. 1990): 1059-61.

6. Mary W. Sprague, "Information-seeking Patterns of University Administrators and Nonfaculty Professional Staff Members," Journal of Academic Librarianship 19 (Jan. 1994): 378-83.

7. Employees of UWO are eligible to be members of the PMA based on a variety of criteria relating to supervision, decision making, and professional credentials. An employee must be at level thirteen of the Hay Scale to be eligible for membership in the association., examples being 
accountants, employee relations officers, counselors, doctors, financial officers, librarians, computer technologists, and engineers. Membership is voluntary and fluxes slightly from month to month. In May 1996, the PMA had a total membership of 363 individuals, from a total of 631 eligible employees. Thus, at the time of the survey, PMA membership was 58 percent of eligible employees. As such, the PMA was considered to be fairly representative of the professional and managerial staff on campus.

8. See the original paper by John C. Flanagan, "The Critical Incident Technique," Psychological Bulletin 51 (July 1954): 327-28; as well as a more recent discussion by David Erlandson, Edward Harris, Barbara Skipper, and Steve Allen, Doing Naturalistic Inquiry: A Guide to Methods (Newbury Park, Calif.: Sage, 1993), 103-7.

9. Ching-Chih Chen and Peter Hernon, Information Seeking: Assessing and Anticipating User Needs (New York: Neal-Schuman, 1982), 17; see also Thomas Pinelli, "The Information-seeking Habits of Engineers," Science \& Technology Libraries 11 (spring 1991): 5-25.

10. See a discussion of the importance of information that is close at hand with respect to the work of engineers, health care professionals, and laywers in Leckie, Pettigrew, and Sylvain, "Modelling the Information Seeking of Professionals," 161-93.

11. Sprague, "Information-seeking Patterns," 380.

12. Thomas D. Wilson, "Information for Research, Information for Practice," in The Information Environment: A World View, ed. D. J. Foskett (Elsevier, 1990), 135.

13. Sprague, "Information-seeking Patterns," 382.

14. Ibid., 382.

15. Watson and Boone, "Information Support for Academic Administrators," 73.

16. For instance, Rebecaa A. Boone, "The Information Needs and Habits of Humanities Scholars," RQ 34 (winter 1994): 203-16, notes that serendipity, browsing and referrals from colleagues play a large role in scholarly work, whereas Mary Folster, "A Study of the Use of Information Sources by Social Science Researchers," Journal of Academic Librarianship 15 (Mar. 1989): 7-11, found that a high percentage of faculty members do not make much use of the library catalog or reference librarians.

17. The term invisible college has been used extensively since the work of Diana Crane, Invisible Colleges (Chicago: Chicago Univ. Pr., 1972), who originally used it to mean a network of scholars engaged in similar research who were in frequent contact with one another regarding research issues and progress. However, the term also could be applied to any group of professionals who share similar work concerns and seek each other's opinions about work-related issues or trends. It has been extended here to the "virtual invisible college" to indicate that, increasingly, contact is taking place via e-mail and the Internet.

18. Julie Bichteler and Dederick Ward, "Information-seeking Behavior of Geoscientists," Special Libraries 80 (summer 1989): 169-78.

19. Watson and Boone, "Information Support for Academic Administrators," 73.

20. Sprague, "Information-seeking Patterns," 383.

21. Ibid., 383.

22. See discussion of roles in C. W. Choo and Ethel Auster, "Environmental Scanning: Acquisition and Use of Information by Managers," Annual Review of Information Science and Technology 28 (1993): 279-314; and Leckie, Pettigrew, and Sylvain, "Modelling the Information Seeking of Professionals."

23. Watson and Boone, "Information Support for Academic Administrators," 68. 